3. Evoh NJ, Akinla O. Reproductive performance after the repair of obstetric vesico-vaginal fistulae. Ann Clin Res. 1978;10:303-306.

4. Baird DD, Steiner AZ. Anti-mullerian hormone: a potential new tool in epidemiologic studies of female fecundability. Am J Epidemiol. 2012;175:245-249.
5. Wilkinson J, Bengtson A, Moyo M, Mwale M, Makanani B, Tang J. Free Communication (Oral) Presentations. Int J Gynecol Obstet. 2015;131(Suppl.5):E72-E313.

\title{
Rape-myth acceptance among students at the University of Cape Coast, Ghana
}

\author{
Sarah D. Rominski ${ }^{1 *}$ | Eugene Darteh ${ }^{2}$ | Michelle Munro-Kramer ${ }^{3}$ \\ ${ }^{1}$ Department of Obstetrics and Gynecology, University of Michigan Medical School, Ann Arbor, MI, USA \\ ${ }^{2}$ Department of Population and Health, University of Cape Coast, Cape Coats, Ghana \\ ${ }^{3}$ School of Nursing, University of Michigan, Ann Arbor, MI, USA \\ ${ }^{*}$ Correspondence \\ Sarah D. Rominski, Department of Obstetrics and Gynecology, University of Michigan Medical School, Ann Arbor, MI, USA. \\ Email: sarahrom@med.umich.edu
}

KEYWOR D : Ghana; Rape-myth acceptance; Sexual violence

Sexual assault, including rape, is an egregious human rights violation that occurs around the world that has become increasingly prevalent on university campuses; by way of example, a large proportion of students in the USA will experience sexual assault during their university career. ${ }^{1}$

In many settings, gender inequality is at the root of sexual assault and rape is justified by blaming victims for putting themselves in a vulnerable position. These "rape myths" affect what is considered rape, minimizing and rationalizing rape. ${ }^{2}$ The objective of the present study was to assess rape-myth acceptance (RMA) among students at University of Cape Coast (UCC), Ghana.

All residential students at UCC who consented to participate were surveyed as part of a project to adapt a sexual-violence prevention program. Study procedures were approved by the institutional review boards of the University of Michigan and UCC. There were two steps utilized to understand RMA; first, the validation and adaption of the Illinois Rape Myth Acceptance Scale (IRMA-SF) ${ }^{3}$ through cognitive interviews and, second, the completion of a survey including the revised IRMA-SF (Box 1). Participants were asked to indicate their level of agreement with 22 statements, allocating scores between 1 (strongly agree) and 5 (strongly disagree). Higher cumulative RMA scores indicated a higher level of rape-myth rejection.

SPSS version 22 (IBM, Armonk, NY, USA) was used to analyze data from 36 female and 35 male participants, aged 19-50 years, who completed the survey. The participants had a mean \pm SD RMA score of $65.6 \pm 14.8$ (range 25-100) using the revised IRMA-SF. Women had a higher level of rape-myth rejection $(71.1 \pm 14.4)$ compared with male participants $(60.1 \pm 13.1)(P<0.001)$. Some IRMA-SF items had much higher levels of agreement than others (e.g. only six participants strongly agreed or agreed with the item, "If the accused 'rapist' doesn't have a weapon, you really can't call it rape" whereas 52 agreed with the statement, "Rape happens when a guy's sex drive goes out of control").

High levels of RMA contribute to greater sexual coercion, and the perpetration of sexual violence by men can be predicted by high RMA. $^{4}$ Similar to findings in Kenya, ${ }^{5}$ the present study found RMA to be high among a student population in Ghana. Interventions are needed to reduce RMA and victim blaming in this setting. A sexualviolence prevention curriculum holds promise to reduce RMA to decrease the perpetration of sexual assaults and to ensure that victims who come forward are not blamed for the violence.

\section{AUTHOR CONTRIBUTIONS}

SDR conceived the study, collected and analyzed the data, and wrote the first draft of the manuscript. ED conceived the study and revised the manuscript. MM-K conceived the study, collected the data, and revised the manuscript. All authors approved of the final version of the paper.

\section{CONFLICTS OF INTEREST}

The authors have no conflicts of interest. 


\section{BOX 1 Adapted rape myth acceptance scale used in the study survey; participants were asked to rate each item between one (strongly agree) and five (strongly disagree).}

If a girl is raped while she is drunk, she is at least somewhat responsible for letting things get out of control

When girls go to parties wearing flirty clothes, they are asking for trouble

If a girl goes to a room alone with a guy at a party, it is her own fault if she is raped

If a girl acts like a flirt, eventually she is going to get into trouble

When girls get raped, it's often because the way they said "no" was unclear

If a girl initiates kissing or hooking up, she should not be surprised if a guy assumes she wants to have sex

When guys rape, it is usually because of their strong desire for sex

Guys don't usually intend to force sex on a girl, but sometimes they get too sexually carried away

Rape happens when a guy's sex drive goes out of control

If a guy is drunk, he might rape someone unintentionally

It shouldn't be considered rape if a guy is drunk and didn't realize what he was doing

If both people are drunk, it can't be rape

If a girl doesn't physically resist sex-even if protesting verbally-it can't be considered rape

If a girl doesn't physically fight back, you can't really say it was rape

A rape probably doesn't happen if a girl doesn't have any bruises or marks

If the accused "rapist" doesn't have a weapon, you really can't call it rape

If a girl doesn't say "no" she can't claim rape

A lot of times, girls who say they were raped agreed to have sex and then regret it

Rape accusations are often used as a way of getting back at guys

A lot of times, girls who say they were raped often led the guy on and then had regrets

Girls who are caught cheating on their boyfriends sometimes claim it was rape

\section{REFERENCES}

1. Cantor D, Fisher B. Report on the AAU Campus Climate Survey on Sexual Assault and Sexual Misconduct. Rockville, MD: Westat; 2015.

2. Boakye KE. Attitudes toward rape and victims of rape: A test of the feminist theory in Ghana. J Interpers Violence. 2009;24:1633-1651.

3. Payne DL, Lonsway KA, Fitzgerald LF. Rape myth acceptance: Exploration of its structure and its measurement using the Illinois Rape Myth Acceptance Scale. J Res Pers. 1999;33:27-68.
4. Chiroro P, Bohner G, Viki GT, Jarvis $\mathrm{Cl}$. Rape myth acceptance and rape proclivity: Expected dominance versus expected arousal as mediators in acquaintance-rape situations. J Interpers Violence. 2004;19: 427-442.

5. Tavrow P, Withers M, Obbuyi A, Omollo V, Wu E. Rape myth attitudes in rural Kenya: Toward the Development of a Culturally Relevant Attitude Scale and "Blame Index". J Interpers Violence. 2013;28: 2156-2178. 